\title{
РЕЗУЛЬТАТЫ ЛИТОДИНАМИЧЕСКИХ ИССЛЕДОВАНИИ ИЗ ОБИТАЕМОЙ ПОДВОДНОЙ ЛАБОРАТОРИИ «ЧЕРНОМОР»
}

\begin{abstract}
Литодинамика береговой зоны до глубин порядка 10 м изучена сравнительно хорошо и освещена в соответствующей литературе (Зенкович, 1962; Лонгинов, 1963; Айбулатов, 1966). Непосредственные измерения процессов перемещения обломочного материала на глубинах свыше 10 м до последнего времени были единичными, несистематическими и кратковременными в основном из-за технических причин. При сравнительно отмелых берегах изобата 10 о отстоит от уреза на несколько сот метров, вследствие чего в периоды штормовых волнений передача информации на берег крайне затруднительна, а использование каких-либо плавсредств на мелководьи полностью исключается.
\end{abstract}

Использование подводной обитаемой лаборатории «Черномор» открыло широкие возможности для исследования скоротечных литодинамических процессов (Айбулатов, Орвику, 1971; Айбулатов 1972). В гечение 1968-1972 гг. в одной из бухт северо-западной части Черноморского побережья Кавказа (рис. 1) на глубинах от 8 до 31 м был проведен комплекс работ, нацеленный на решение следующих задач: а) исследовать динамику рельефа до глубины 31 ; б) измерить объемы аккумуляции (или размыва) обломочного материала в различных частях склона; в) изучить режим взвешенных наносов в придонном слое; г) нсследовать механическую дифференциацию осадков и динамику микроформ донного рельефа; д) определить эпюры скоростей течений и микропульсаций в придонном слое.

Все перечисленные задачи подчинены установлению нижней границы береговой зоны и нахождению хотя бы качественного перехода к литодинамическим процессам шельфа, ибо, по справедливому замечанию В. В. Лонгинова и А. А. Аксенова (1968), это - первоочередная задача литодинамики моря, решения которой ждут литология и инженерная геология моря. Крайне важно также определение глубины, ограничивающей в различных условиях обратимые перемещения наносов.

Примененная нами методика исследований предусматривала проведение ряда измерений на специальных экспериментальных полигонах на глубинах 10, 15, 20, 25 и 31 м (Айбулатов, Орвику, 1971; Айбулатов, 1972).

Анализ данных по морфодинамике свидетельствует о том, что знакопеременные процессы происходят на полигоне, расположенном на глубине $10 \mu$. Здесь в зависимости от повторяемости штормовых волнений идет намыв или размыв (рис. 2). При большей повторяемости волнений штормовой силы происходит размыв (1969-1970 гг.), при 
меньшей - намыв (1968-1969 гг.). Подводный склон ниже $10 \mu$ в течение всего срока наблюдений отличался стабильным процессом аккумуляции, причем еe величина уменьшалась в сторону моря.
- Mayta gля kреn- nehua npubopob
ใ Нскусстьенный PUФ
- 5yu яkорные
- Плаббаза
1 "Черномор"
$\nabla$, Cnpyr"

- Буробая установка

- Полurohol reonoruyecrue

- Euonoruqeckuú стенg

$\triangle$ Коррозионный стенg

I Профили gля - Luзмерения

Рис. 1. Схема полигонов и расположение п/л «Черномор» в 1968-1972 гг.

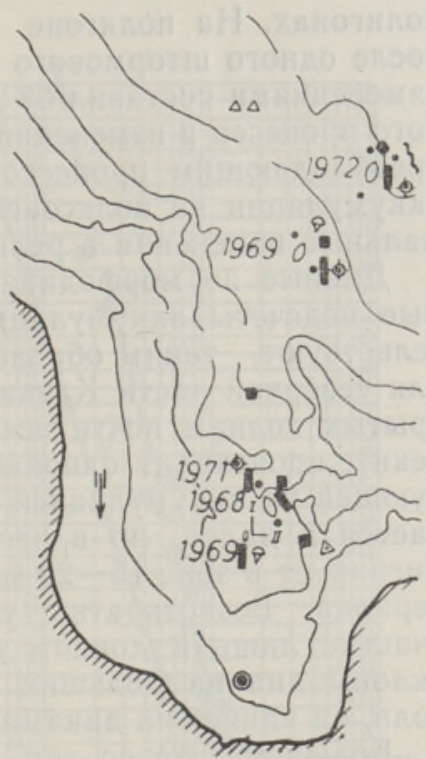

Неравномерность аккумуляции обломочного материала на профиле объясняется, очевидно, различной гидродинамической активностью водной толщи. Во время волнений, направленных по оси бухты и имеющих наибольшую повторяемость, в бухте возникает компенсационный отток в виде разрывных течений, достигающих значительных скоростей (более 1,5 м/сек). Скорости разрывных течений постепенно уменьшаются в сторону моря. В зоне затухания этих течений и происходит отложение материала. Зона глубин $10-12$ м, очевидно, может находиться в районе размыва и намыва дна. В периоды значительной гидродинамической активности для этой зоны характерен отрицательный баланс материала, т. е. она служит не только транзитной зоной для наносов, идущих от берега в море, но и в некоторой степени самим источником.

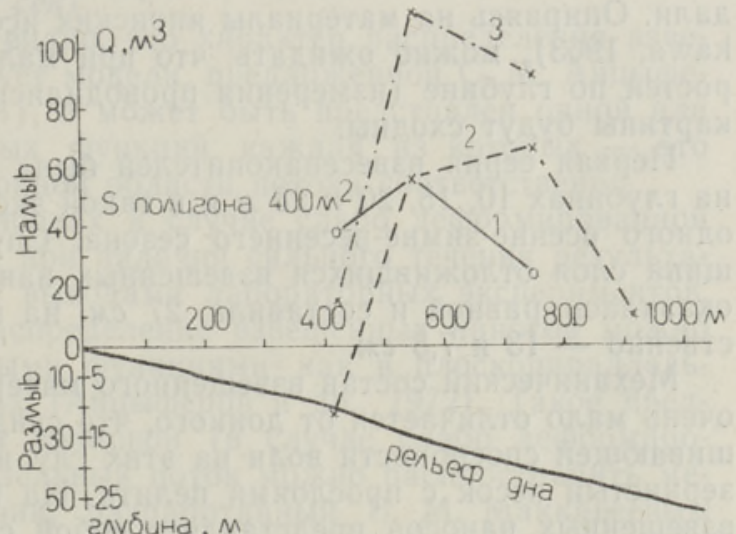

Рис. 2. График изменения объемов аккумуляцин (размыва) обломочного материала на полигонах за 1968-1970 гг. (по Айбулатову, 1972): октябрь 1968 - август $1969(1)$, август 1969 - май 1970 (2), октябрь 1968 - май 1970 (3).

Полоса дна с глубинами 15-31 $м$ - это зона, где происходит ус. тойчивая аккумуляция обломочного материала. За два года измерениі на полигоне $15 \mu$ отмечен намыв грунта в объеме $120 \mathrm{M}^{3}$. С увеличением количества волнений штормовой силы максимум намыва смещается в сторону моря на глубину до 20 м (в 1969-1970 гг. волнений с высотой волны более 2 м было втрое больше, чем в 1968-1969 гг.). На глубине 25 м степень аккумуляции значительно меньше, чем на вышележащих 
полигонах. На полигоне 31 , к сожалению, проведены замеры лишь после одного штормового волнения $(h=3,0 \mu)$, период между крайними измерениями составил 38 дней. Интересно отметить, что однонаправленного процесса в изменениях рельефа на этом полигоне не отмечено, хотя преобладающим процессом и здесь оказался аккумулятивный. Объем аккумуляции на полигоне за указанный срок составил $2,8 \mathrm{\mu}^{3}$, а максимальные изменения в рельефе - $7 \mathrm{~cm}$.

Данные по морфодинамике и произведенные на их основании пря мые подсчеты аккумуляции (размыва) обломочного материала свидетельствуют, таким образом, о том, что в бухтах, весьма характерных для северной части Кавказского побережья Черного моря (хорошо открытых волнам почти всех морских румбов и с наличием маловодной реки), происходит однонаправленный перенос наносов в море с последующей их аккумуляцией в зоне глубин 15-20 м. Этот процесс наблюдается и далее, но в несколько раз слабее. Максимум аккумуляции мигрирует в зоне 15-20-метровой глубины в зависимости от активности периода. Безвозвратно утерянный для пляжа материал принимает участие лишь в донном осадкообразовании, хотя косвенно уменьшая уклоны дна на больших глубинах через изменение хода деформации волн, он влияет на динамическое состояние береговой зоны в целом.

Большой интерес для литодинамики внешней части береговой зоны представляют данные о режиме взвешенных наносов в придонном слое на глубинах $10-31$ м. Для его изучения нами применялись различные взвесеуловители (точнее, взвесенакопители), которые устанавливались на треногах или вертикальных стойках на строго фиксированных расстояниях от дна. С их помощью мы не могли определять распределеңие абсолютной концентрации взвешенных наносов, однако информацию об изменении их относительного содержания по профилю и вертикали они дали. Опираясь на материалы японских исследователей (Hom-ma, Horikawa, 1963), можно ожидать, что при малом изменении волновых скоростей по глубине (измерения проводились в толще воды 3 м) эти две картины будут сходны.

Первая серия взвесенакопителей была установлена в 40 cм от дна на глубинах $10,15,20$ и $25 \mu$ и в такой экспозиции изучалась в течение одного осенне-зимне-весеннего сезона. Спустя указанный период толщина слоя отложившихся взвешенных наносов на глубинах 10 и $15 \mathrm{M}$ оказалась равной и составила 27 см, на глубинах 20 и 25 м соответственно - 13 и $7,5 \mathrm{~cm}$.

Механический состав взвешенного материала на глубинах 10 и $15 \mathrm{M}$ очень мало отличается от донного, что свидетельствует о большой взвешивающей способности волн на этих глубинах. Это в основном среднезернистый песок с прослоями пелита. На глубинах 20 и 25 м колонка взвешенных наносов представляет собой своеобразный слоеный пирог, состоящий из пелита, тонко- и мелкозернистого песков. Толщина слоев пелита составляет в среднем около 3 см, слоев песка - всего лишь несколько миллиметров. В колонке взвесей, взятой с глубины $10 \mathrm{M}$, песчаных прослоев больше и их мощность доходит до 2 см, граница между пелитом и песком во всех случаях довольно резкая. Очевидно, песчаные слои фиксируют собой наличие высоких придонных скоростей, т. е. штормовые периоды, а пелит - периоды после штормов, когда из толщи воды начинают выпадать полновзвешенные наносы.

Помимо сезонных исследований взвешенных наносов, нами были проведены серии замеров взвесей в течение отдельных, разных по силе волнений и в периоды штилевой погоды. Для этого на треногах, pacставленных на глубинах 15, 20 и $25 \mu$, в придонном слое 3 м была за- 
Рис. 3. Примеры распределения взвешенных наносов в придонном слое на глубине 30 м при различных гидродинамических режимах: - штиль, однонаправленное течение, $0,6-0,7 \mathrm{M} /$ сек; + штормовое волнение, $h=3,0 \mathrm{M}, T=8 \mathrm{ce \kappa}$; $Z / H$ - относительная глубина, $S_{(z)}$ концентрация взвеси на глубине $Z$.

креплена вторая серия взвесенакопителей. На глубине 30 м была установлена 6,5-метровая мачта со взвесенакопителями, расставленными по всей высоте мачты на расстояниях $10-15 \mathrm{~cm}$ друг от друга, и вертушками БПВ на расстояниях 0,$5 ; 1,0 ; 2,0 ; 3,0$ и 4,0 м от дна.

На рис. 3 приведены результаты двух замеров распределения взвешенного материала по вертикали в 6,5-метровой придонной толще на глубине 30 м. Первая

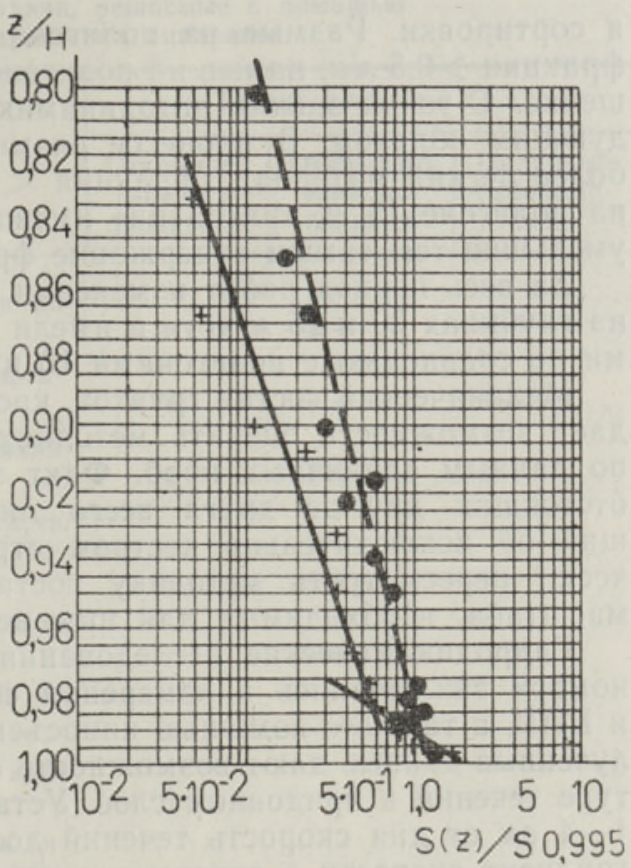
серия измерений получена во время действия однонаправленного течения при отсутствии волнения, но при значительных скоростях течений $(0,6-0,7$ м/сек на высоте 3 м от дна), вторая - во время штормового волнения при отсутствии однонаправленного течения $(h=3,0 \mathrm{M}, T=8,0$ сек).

Из приведенных графиков видно, что характер распределения взвешенного материала соответствует модели, предложенной С. М. Анцыферовым и Б. А. Шуляком (1971), и может быть представлен одной или суммой двух экспоненциальных функций, каждая из которых - это вклад основной толщи и придонной области потока соответственно.

Полученные в морских условиях в случае слабо деформированной волны или в штилевую погоду при наличии сильного течения результаты качественно согласуются с выводами лабораторных экспериментов, в соответствии с которыми распределение взвешенных наносов можно представлять экспоненциальными функциями как в плоскопараллельном, так и в волновом потоках (Анцыферов и др., 1972). Такое представление показывает, что на волновой (в случае слабо деформированной волны) и плоскопараллельный поток можно распространить механизм турбулентной диффузии, разработанный В. М. Маккавеевым (1931).

На протяжении всего периода работ из подводной лаборатории «Черномор» на полигонах близ каждого репера отбирались пробы грунта с последующим их механическим анализом. Материалы по динамике механического состава донных осадков во времени свидетельствуют о большой литодинамической активности зоны глубин $10-25$ м. Среднее значение $M d$ на полигонах, определенное по 25 пробам, колебаний во времени почти не испытывает, хотя $M d$ отдельных проб, отстоящих друг от друга лишь на 5-10 (Айбулатов, 1972). Для оценки процессов механической сортировки более чувствительной величиной оказалось среднее содержание фракции $>0,5$ мм. При рассмотрении изменений этой величины во времени за 1968-1970 гг. обнаружена связь между процессами морфодинамики 
и сортировки. Размыв на полигоне $10 \mu$ повлек за собой увеличение фракции $>0,5$ мм, намыв на полигоне 15 м за это же время - ее уменьшение. С точки зрения литодинамики эту связь можно объяснить следующим образом. В процессе размыва с полигона 10 м был вынесен более легкий материал (фракция $<0,5$ мм), который затем отложился на полигоне $15 \mu$, «разбавив» имевшийся там обломочный материал и уменьшив тем самым содержание фракции $>0,5$ мм.

За весь период работ изменения в механическом составе материала на глубинах 20 и 25 м хотя и имели место, но были менее значительными по сравнению с полигонами 10 и $15 \mathrm{M}$.

Механический состав грунтов, кроме литодинамической информации, дает возможность оценить методику существующих грунтовых съемок по данным единичных проб. Факт значительных колебаний $M d$ проб, отстоящих друг от друга всего лишь на 5-10 $м$, свидетельствующий об исключительно пестром строении грунтов, заставляет критически пересмотреть методику составления грунтовых карт крупного масштаба, необходимых для инженерно-геологических целей.

Гидродинамические исследования из подводной лаборатории «Черномор» заключались в измерении скоростей течений приборами ВДК и БПВ, а также с помощью киносъемки окрашенного облака воды. Полученные данные дают возможность сделать некоторые выводы о структуре течений в придонном слое. Установлено, что даже на расстояниях $1-4$ см от дна скорость течений достигает нескольких $c м / c е \kappa$, так что градиент скорости в сантиметровом слое у дна велик. Скорость у дна пульсирует с периодами, по-видимому, близкими к периодам прохождения групп волн. Существенны также данные об изменении скоростей течений в придонном слое на глубине 30 в штилевую погоду (до $0,7 \mathrm{M} / \mathrm{ce \kappa})$.

С помощью п/л «Черномор» был получен ряд косвенных данных о разрывных течениях в бухте. Так, при одном 4-балльном волнении подводная лаборатория, имеющая отрицательную плавучесть $3,9 \mathrm{~T}$, совершила «подводный рейд» в сторону моря длиной около $70 \mathrm{~m}$. Это движение «Черномора» мы склонны отнести за счет действия разрывных течений (Айбулатов, Орвику, 1971). Интересно отметить, что лаборатория совершила этот путь не только периодически взвешиваясь под действием волнения, но и волоком, что свидетельствует о высоких скоростях придонных разрывных течений.

Тот же «Черномор», находясь на плаву в районе глубин $12-14$ м во время 6-балльного волнения, дал неоценимую информацию о периодичности действия разрывных течений. Дело в том, что разрывные течения в бухтах непостоянны, для их возникновения необходимо создание определенного градиента уровня в прибрежной и открытой частях моря. Для этого нужно время и тем большее, чем больше коэффициент вогнутости бухты. Кроме того, это явление зависит от параметров волн и ветра. При описанных выше условиях заякоренный «Черномор» периодически прибивался волнами к берегу, а затем резко, с большой скоростью устремлялся в сторону моря. Такие миграции «Черномора» повторялись через каждые 5-6 мин (через 50-60 волн).

При выполнении подводных исследований литодинамики нижней части береговой зоны был сделан ряд методических разработок. В частности, опробован способ бурения, при котором буровой станок устанавливается непосредственно на дно. Созданная и опробованная совместно с лабораторией подводных исследований «Ихтиандр» (Донецк) подводная буровая установка (ПБУ) позволяет получать керны с ненарушенной структурой с глубины до $30 \mu$ в осадочных и коренных поро- 
Основные геологические задачи, решаемые с помощью различных гипербарических аппаратов

\begin{tabular}{|c|c|c|c|}
\hline \multirow[b]{2}{*}{$\begin{array}{c}\text { Научные задачи и } \\
\text { проблемы }\end{array}$} & \multicolumn{3}{|c|}{ Типы аппаратов } \\
\hline & $\begin{array}{l}\text { Открытого } \\
\text { типа ста- } \\
\text { ционарные }\end{array}$ & $\begin{array}{l}\text { Открытого } \\
\text { типа мо- } \\
\text { бнльные }\end{array}$ & $\begin{array}{l}\text { Палубный } \\
\text { барокомп- } \\
\text { лекс }\end{array}$ \\
\hline $\begin{array}{l}\text { Исследование литодинамических процессов на } \\
\text { шельфе }\end{array}$ & + & ++ & ++ \\
\hline $\begin{array}{l}\text { Исследование геолопического и геоморфологи- } \\
\text { ческого строения каньонов }\end{array}$ & & ++ & ++ \\
\hline $\begin{array}{l}\text { Исследование геологического строения вершин } \\
\text { подводных вулканов }\end{array}$ & & $+t$ & $+t$ \\
\hline $\begin{array}{l}\text { Исследование физико-механических свойств } \\
\text { грунтов (влажности, пористости, липкости, со- } \\
\text { противления сдвигу) }\end{array}$ & + & + & - \\
\hline $\begin{array}{l}\text { Иоследование гидродинамических процессов в } \\
\text { придонном слое }\end{array}$ & & + & + \\
\hline $\begin{array}{l}\text { Разведка и картирование морских россыпей по- } \\
\text { лезных иокопаемых }\end{array}$ & & ++ & + \\
\hline $\begin{array}{l}\text { Исследование биологической переработки дон- } \\
\text { ных отложений }\end{array}$ & + & & + \\
\hline $\begin{array}{l}\text { Детальное обследование древних береговых ли- } \\
\text { ний, изучение геологических обнажений с кру- } \\
\text { тыми стенками }\end{array}$ & & + & + \\
\hline $\begin{array}{l}\text { Эксперименты с искусственными изменениями } \\
\text { рельефа дна и субстрата для исследования ли- } \\
\text { тодинамики в различных условиях среды }\end{array}$ & & & + \\
\hline $\begin{array}{l}\text { Контроль за работой приборов и аппар } \\
\text { спускаемой с плавсредств в делях разр } \\
\text { новых средств исследования }\end{array}$ & & + & ++ \\
\hline
\end{tabular}

Примеч ание: одним крестиком обозначена возможность выполнения задачи тем или иным подводным аппаратом, двумя - наиболее рациональное и информативное использование аппарата для выполнения задачи.

дах (Айбулатов и др., 1973). В результате подводных испытаний ПБУ была пробурена скважина 11,2 м на глубине 7 м. Испытания показали, что принятый способ безнасосного бурения достаточно эффективен. Медико-физиологические исследования свидетельствуют, что труд подводных бурильщиков связан со значительными затратами энергии, поэтому необходимо создание современной индивидуальной системы жизнеобеспечения для легководолазов-бурильщиков.

В заключение остановимся на перспективах применения обитаемых гипербарических устройств (ОГУ) в геологии. Опыт проведения геологических исследований как по программе «Черномор», так и по другим программам (например «Тектайт», «Гельголанд», «Силаб») демонстрирует уникальные возможности, предоставляемые геологам ОГУ. При этом до самого последнего времени использовался только один из видов ОГУ, а именно подводные лаборатории. Но геологические исследования с неменьшим успехом могут быть осуществлены с помощью судового водолазного комплекса, обеспечивающего возможность длительной работы людей под водой, а также с помощью автономных аппаратов, имеющих гипербарический отсек.

В таблице приведена сравнительная оценка перспективности применения различных видов ОГУ для решения широкого круга геолого-гео-

6 ENSV TA Toimetised. $\mathrm{K} * \mathrm{G}-41974$ 
морфологических задач. На основании данных, приведенных в этой таблице, а также учитывая высокую эксплуатационную стоимость подводной лаборатории, дальнейшее развитие подводных геологических исследований следует, на наш взгляд, связывать с использованием судовых водолазных комплексов и автономных мобильных аппаратов с гипербарическими отсеками. Несомненно, что все перечисленные в таблице задачи найдут наиболее успешное решение лишь при условии применения комплекса методов. Одним из этих методов является использование ОГУ, позволяющих получать по каждому из названных вопросов уникальную информацию, которую нельзя получить иным способом.

Приведенная таблица - по-видимому, первая попытка оценить различные обитаемые гипербарические аппараты с точки зрения возможности их использования для решения геолого-геоморфологических задач. Литература по этому вопросу очень малочисленна.

Существуют две крайние точки зрения на применение подводных аппаратов для изучения океана. В соответствии с одной из них преимущественно следует развивать технические средства, обеспечивающие исследователю возможность непосредственного выхода в воду, в соответствии со второй - океан следует изучать только с помощью необитаемых аппаратов (измерительных и телеметрических комплексов).

На основании анализа литературы о применении различных обитаемых аппаратов, а также используя личный опыт, накопленный в течение многих лет работы по организации геологических исследований с применением водолазного труда, авторы стоят на позициях разумного сочетания возможностей человека и автомата. При исследовании и освоении глубин океана, как и космического пространства, непосредственные выходы человека в изучаемую среду оказываются весьма желательными, а в ряде случаев просто необходимыми, так как возможности замены человека автоматами пока еще недостаточно широки. Кроме того, целый ряд исследований, по-видимому, всегда будет требовать непосредственного пребывания человека в толще воды.

\section{Л И ТЕ Р А Т У Р А}

А й б ул а тов Н. А. 1972 . Новый метод исследования литодинамики шельфа. Доклады симпозиума по инженерно-геологическим условиям шельфовой зоны Черного моря (Батуми, 1971). Тбилиси.

А й бул а то в Н. А. 1966. Исследование вдольберегового перемещения песчаных наносов в море. $M$.

А йбул атов Н., О рвику К. мл. 1971. О возможностях использования подводной лаборатории «Черномор» для геологических исследований. Изв. АН ЭССР, Хим. Геол, 20, № 2.

Ай 6 улатов Н. А., Барац Ю. М., Зубченко А. Г., Киклевич Ю. Н. 1973. Испытания подводной буровой установки. Разведка и охрана недр, № 6 .

Анц ыферов С. М., Шуляк Б. А. 1971. Особенности распределения взвешенных твердых частиц в поступательных потоках. Тр. Союзморниипроекта, вып. 30 (36).

Анцы феров С. М., Косьян Р. Д., Лонгинов В. В. 1972. Экспериментальное исследование перемещения наносов под действием волнения и спутного течения. Тр. Союзморниипроекта, вып. 34 (40), М.

Зен кович В. П. 1962. Основы учения о развитии морских берегов. М.

Л онгино в В. В. 1963. Динамика береговой зоны бесприливных морей. М.

Л онгинов В. В., Аксенов А. А. 1968. Литодинамика моря, ее содержание, задачи и перспективы. Океанология, VIII, вып. 4.

М акка в е ев В. М. 1931. К теории турбулентного режима и взвешивания наносов. Изв. ГГИ, вып. 32.

Hom-ma M., Horikawa K. 1963. Suspended sediment due to wave action. Proc. Eighth Conf, on Coastal Engineering. Mexico.

Южне отделение Института океанологии Академии наук СССР
Ннститут геологии Академии наук ЭстССР
Поступнла в редакцию 30/XI 1973 
N. AIBULATOV, R. KOSJAN, K. ORVIKU jun.

\section{ASUSTATUD ALLVEELABORATOORIUMI «TSERNOMOR» ABIL TEOSTATUD LITODUNAAMILISTE UURIMISTE TULEMUSI}

Allveelaboratooriumi «Tšernomor» abil 1968.-1972. aastal ühes Musta mere Kaukaasia ranniku loodeosa lahes (joon. 1) 10, 15, 20, 25 ja $31 \mathrm{~m}$ sügavusel asunud eksperimentaalsetel polügoonidel teostatud uurimistöö eesmärgiks oli selgitada rannavööndi ja šelfi vahelist piiri. Selleks jälgiti muutusi kiirelt toimuvates litodünaamilistes protsessides, nagu setete rändes ja mehaanilises koostises ning põhjalähedases vees hôljuva settematerjali hulgas ja mehaanilises koostises. Peale selle teostati mitmed metoodilised uurimised, katsetades ka puurimist mere põhjas paikneva puurimisseadmega.

Artikli lõpus vaadeldakse mitut tüüpi asustatud hüperbaariliste seadmete kasutamise võimalusi merepõhja geoloogia uurimisel.

N. AIBULATOV, R. KOSYAN, K. ORVIKU jun.

\section{RESULTS OF SOME LITHODYNAMIC TESTS \\ (EXPERIMENTS ON BOARD THE INHABITED SUBMARINE LABORATORY "CHERNOMOR")}

The article gives the results of fast-floating lithodynamic processes which were obtained through the "Chernomor", an inhabited submarine laboratory. The lab was stationed in one of the northwestern bays of the Black Sea, and the tests covered the depth range from 8 to $31 \mathrm{~m}$ (Fig. 1).

The tests were carried out with certain aims in mind: to set the lower boundary of the near-shore zone, to find out at least a qualitative transition onto the lithodynamic processes of the shelf, to determine how deep lies the limit of reversible displaces of sediment. To attain these results, special experimental polygons were used in a series of tests at the depths of $10,15,20,25$ and $31 \mathrm{~m}$.

Here we present some results of the repeated tests at volumes and composition of the displacing heterogenous sediment. We also discuss the regime of suspended sediment in the bottommost layer and its composition.

Quite a few points on the technique side got worked out, in particular the method of boring. For this the boring machine was placed onto the immediate bottom, and the aquanauts attended to it in the course of tests.

Lastly, the authors tried to give a comparative estimation what the prospects of underwater inhabitable devices would be in order to solve a wide range of geological and geomorphological problems (Table). 